\title{
School Radio: Finding Innovation in Reaching Remote Learners in Belize
}

\author{
Jean Denison Kirshner* \\ Douglas County School District, Colorado, USA \\ Corresponding author: Jean Denison Kirshner, E-mail: jean.kirshner@dcsdk12.org
}

\author{
ARTICLE INFO \\ Article history \\ Received: June 05, 2020 \\ Accepted: July 18, 2020 \\ Published: July 31, 2020 \\ Volume: 8 Issue: 3 \\ Conflicts of interest: None \\ Funding: None \\ This paper reports a part of the results \\ of the Belize Education Project \\ co-founded by the author. For more \\ information, visit Belizeeducationproj- \\ ect.org
}

\begin{abstract}
This case study on Belize educators during the COVID-19 school closures examines the innovative approach the educators of this country took. As many schools across the globe swiftly pivoted to online learning during the COVID-19 school closures, the educators of Belize recognized that digital learning would leave out their marginalized students who did not have internet connectivity. Instead, the educators of Belize drew on the history of their country, using school radio to reach their youngest citizens located in remote locations without internet. This innovative solution, reaching students in villages without internet, required the collaboration of Belize's teachers and radio broadcasters.
\end{abstract}

Key words: Belize, Central America, COVID-19, School Closures, School Radio

\section{INTRODUCTION}

\section{Purpose, Task, and Importance}

The purpose of this case study is to examine the innovative response from Belizean educators in using their national radio to reach remote learners. It also examines the impact this had on teachers in their country. The importance of this study offers global educators lessons in not just diverse ways to deliver instruction, but also in hope, resilience and the transformation of teacher identity in the process.

For the purpose of this article, a narrative approach was chosen to present the Belizean educators' work. When Goodson (1992) was studying teachers' lives, he noted that, "our minds work with truth in narrative" (p. 225). Bruner (1993) also inspired narrative tropes and strategies to engage in this representational process. For example, he wrote, "our capacity to render experience in terms of narrative" as "an instrument of making meaning that dominates much of life in culture" (p. 97). A narrative approach was also chosen in order to capture what was real, what was true; not report just "the facts" of COVID school closures, globally and in Belize, but to convey what these facts had to say about this human experience. Drawing on Loh (2013), a narrative approach best allowed "others to have a vicarious experience of being in the similar situation and thereby being able to understand the decisions made and the emotions felt by the participants in the study" (p. 10). In other words, a narrative could best achieve verisimilitude, which Schwandt (2015) defined as "evocative power or sense of authenticity," which could draw the readers "into the experiences" of the Belizean colleagues in such a way that their experiences could be felt (p. 323). The story of Belizean educators' and other stakeholders' challenges and responses, along with the impact it had on their identity and newly formed connections was most appropriately presented as a narrative.

\section{Background and Literature}

As a small country in Central America, tucked in between Mexico and Guatemala, Belize entered the global crisis of COVID-19 with the rest of the world. Along with schools across the globe, the classroom doors of this small nation closed in March of 2020. Belize is not a resource rich country. It was defined by the World Economic Outlook and Financial Surveys in International Monetary Fund (2015) as one of the "Heavily Indebted Poor Countries and Low-Income Developing" (p. 152). Belize relies heavily on tourism. Specifically, the International Monetary Fund (2019) claimed that one third of Belizean jobs come from tourism (p. 5) Therefore, the economic status of Belize has been exasperated by COVID-19. Thomas (2020) noted that a heavy reliance on tourism presents challenges to "raising domestic resources" (para 3). The economic status of Belize limits the resources it can offer to classrooms, teachers, and students, especially in a global crisis. 
The speed in which classrooms closed their doors, not only in Belize, but across our entire planet left educators breathless. Based on the assumption that large-scale or national closure of schools could reduce the transmission of COVID-19, schools across the world closed (Viner et al., 2020). In the period of a few weeks, UNESCO (2020) reported that 1.19 billion learners were out of school, causing Director-General Audrey Azoulay (2020) to declare, "Never before have we witnessed educational disruption at this scale" (para 1). The sentiment was echoed by Winthrop (2020a) who noted that "March 2020 will forever be known in the education community as the month when almost all the world's schools shut their doors" (para 1) These global school closures are historically unprecedented. Winthrop (2020b) continued:

even compared to school closures during global crisessuch as the 1918 Spanish flu pandemic where 40 U.S. cities closed schools, and World War II where in the UK one million children were out of school - the level of education disruption is much greater today. (para 1)

She continued to explain, "Today, 90 percent of the world's young people are enrolled in primary school now compared to 40 percent in 1920" (para 4). The enormity of the school closures impacted the entire planet.

The stress that these school closures put on teachers was felt globally. Kim and Asbury (2020) studied teachers in England during the COVID-19 closures. One of their participants described the experience "like a rug had been pulled from under you" (p. 7). Another participant in their study described it this way: "I guess it felt a bit like, you know, you're shown the diagram of how the parachute works and then you're pushed out of the plane" (p. 7). Whole new ways of reaching students were shaking teachers across the globe.

As classroom doors swiftly closed across the world, educators were left scrambling to come up with alternatives to keep their students learning. Winthrop (2020a) explained, "the speed of these closures and the rapid move to distance learning has allowed little time for planning or reflection" (para 1). Some countries closed the schools without an immediate alternative, such as Japan as Rich, Dooley and Makiko (2020) noted in the New York Times. China, on the other hand, immediately opted for online learning as an alternative to classroom instruction. Zhang, Wang, Yang, and Wang (2020) described an emergency policy initiative called "Suspending Classes Without Stopping Learning" which was launched by the Chinese Ministry of Education to switch teaching activities into large-scale online teaching while schools were closed (p. 1). Educators around the world also sought to rapidly replace physical attendance at school with online education.

The speed in which the planet's educators gallantly responded to set up school online was impressive and even commendable. A swift response to their students' learning needs offered a critical sense of normalcy in this global crisis. As noted by Azzi-Huck and Schmiss (2020) from the World Bank Task Force, the attempt to immediately move learning to an alternative platform could help students "cope or maintain some normalcy during a crisis and recover more quickly" (para 1). Concurring with those at the World Bank
Task Force, and in the trenches on the front line of teaching herself, Kimberly Hueston, an Infant I teacher in Belize asserted, "I cannot stress enough how important it is to provide our students, globally, with a sense of normalcy and familiarity in such a rapidly changing or fluid environment" (Heusner, personal communication, [email]. May 21, 2020). A rapid response from global educators sought to give students a seamless sense of continued learning and normalcy.

\section{Internet is Inaccessible to Remote and Marginalized Learners Globally}

The grim reality of online learning, however, is the inequitable way it impacts our very most vulnerable young learners. Winthrop (2020b) expounded "for students who do not have access to technology, books, food, or literate adults at home, remote learning runs the risk of drastically widening the gap between young people with those resources" (para 18). In the midst of this global crisis, it is more urgent than ever to be mindful of our marginalized students. UN Deputy Secretary General Amina Mohamed (2020) stressed, "this is not a time to deepen inequalities. It is a time to invest in education's power to transform. Our responsibility as a global community is to leave absolutely no one behind" (para 6). A editorial from the Lancet (2020) concurred, noting "Education shapes lives - it is key to lifting people out of poverty and reducing socioeconomic and political inequalities" (para 2). The writers continued to explain that historic inequities of education are more even more pronounced now. "Today — as the world is shaken by the COVID-19 pandemic and the long-overdue recognition of structural racism - the centrality of education and schools to societies has become much clearer" (para 2). Relying on the internet and devices to reach marginalized learners exasperated this historic reality.

As China was leading the world in moving the learning of all of their students to a digital platform, Zhang et al. (2020) recognized "the network coverage in remote areas (in China) is insufficient, which may further lead to educational inequity (p. 3). Lancker and Parolin (2020) addressed the concern of reaching our most vulnerable children on a global level in their report for The Lancet, where they explained many of our world's young learners live in conditions that make online learning impossible because "online learning environments usually require computers and a reliable internet connection" (para 4). A small percent of families living in developing countries have internet access. Vegas (2020) noted that "only 36 percent of residents of lower-middle income countries have access to the internet, a statistic that cannot easily be improved during the pandemic" (para 3). As Italy moved to remote learning, Principi and Esposito (2020) noted that in areas of the Italy, " $41 \%$ of the households did not have a tablet or a personal computer and that among families with at least 1 child, only $14.3 \%$ could guarantee distance learning" (para 3). Resource-rich nations struggle to meet reach marginalized students through online learning as well. Thomas (2020) noted that the move to internet learning "has exposed the glaring digital dived that exists even within the wealthiest countries" (para 4). For instance, teachers in England reported that reliable internet was inaccessible to 
marginalized students. Kim and Asbury (2020) quoted one of their participants:

If somebody in authority asked them (the students) the question, 'do you have internet access?' they, of course, they would say 'yes.' But in reality, what they have is a phone, that's Mum's phone that she can get the internet on ... And Mum is terrified of wasting the data because she's got no money to buy some more. (p. 13)

Globally internet was inaccessible marginalized learners. This had become an international reality and challenge during COVID-19 remote learning.

\section{Questions and Hypothesis}

The impossibility of learning in the classroom during the COVD-19 pandemic, along with the impossibility of reaching marginalized learners who lacked internet connections and devices, simultaneously presented. What solutions could emerge in this new reality? The research questions became: What options are available to reach students in a more inclusive method? How could a more innovate and inclusive process impact all stakeholders involved? It was hypothesized that the use of the national radio to reach students could impact not only students, but teachers' identities as innovators and connecters.

\section{DATA DISCUSSION}

\section{Members and Methods}

The data for this article was collected independently through a variety of methods including interviews and focus groups conducted on a variety of virtual platforms, emails, and Facebook messaging conversations. Teachers, members of the Belize Ministry of Education, a Belize radio executive, and families all contributed to this set of data. In addition to collecting the experiences of the members who have been impacted by learning during the COVID-19 time in Belize, data collection also included radio lessons from the Belize Ministry of Education found on their website.

Multiple methods were used to collect data, as well as a variety of representatives of this work (data sources), in order to demonstrate a comprehensive understanding of this phenomena, or to triangulate the data. As described by Bazeley (2013), the use of triangulation as a strategy for validation involves "independently obtaining one or more alternative sources of data" (p. 406) and further "checking to see of the inferences that you draw from the data are comparable" ( $p$. 406). Just as significant to this research as triangulation of the data, was the attention to the trustworthiness in coming to understand the experience of using school radio in Belize. In her description of trustworthiness, Moss (2004) referred to "trustworthiness as an art ... where multiple voices or multivoicedness is allowed to flourish" (p. 363). In this research, multiple voices and points of view have been included.

After the data had been compiled, several themes emerged in the findings. These themes included the challenge of meeting learners without internet, a rich history of the innovative use of radio for learning in Belize, teachers' commitment to continue reaching all students, the continuous reconstruction of identity that came with challenge of shifting instruction, the deepening connections through his experience, and finally hopes and fears for better reaching young Belizeans going forward. As these themes emerged in the data, the discussion is embedded in the findings. This was the most authentic and powerful way to unpack both the findings and the discussion.

\section{Internet is Inaccessible to Remote and Marginalized Learners of our Belize}

As a teacher of five-year-old students in Belize, Heusner, passionately discussed the challenge of her students' inability to access online learning, "Suddenly digital learning is the 'in-thing.' But, what about our children from lower socio-economic backgrounds who are left out because there are some remote villages where electricity is still a struggle?" (Heusner, personal communication, [email]. May 21, 2020). The Chief Education Officer of Belize Ministry of Education, Carol Babb, emphatically concurred with her teacher, "At first everybody said, 'oh e-teaching, e-learning.' I said, 'We must also ensure that we provide for the most at risk, for the most marginalized. We need to ensure that every, every, every single child has access to learning" (Carol Babb, personal communication, [phone interview], May 18, 2020). Both Belizean educators echoed Lancker and Porolin's (2020) advice that "teachers should also consider how to adapt their learning materials for students without access to wireless internet, and a computer" (p. 243). Finding alternatives to internet learning was critical.

How could educators quickly reach remote students on a large - or national scale - without internet? The charge of meeting the needs of the youngest and most vulnerable citizens of their country was daunting, perhaps discouraging. Yet, the collective community of Belizean educators were determined, perhaps led by hope, or perhaps led by desperation. As Holland Lachicotte, Cain, and Skinner (1998) described, this became a "processes whereby human collectives and individuals often move themselves - led by hope, desperation, or even playfulness" (pp. 6-7). With these very human characteristics, the educators of Belize were of the same mind as Angelina Jolie (2020) United Nations High Commission for Refugees Special Envoy, when she stressed, "We must speed up the ways we share experience, and help the most vulnerable, whether or not they have internet access" (para 4). Nash and Eyon (2020) suggested that "schools make the best use of all available communication means" (para 11). In particular they discussed the use of other possibilities, "such as using low-bandwidth options such as radios" (para 11)

Other countries with limited resources have also utilized radio for reaching remote learners. The use of radio for education was studied in India by Chandar and Sharma (2003), who found that radio was "capable of delivering high quality educational programming to highly diversified audiences located across broad geographical expanses - all at a low per unit production cost" (p. 2). They continued to discuss the advantages of using radio including: "(1) improved educational 
quality and relevance; (2) lowered per student educational costs; and (3) improved access to education, particularly for disadvantaged groups" (p. 2). School radio in Pakistan a decade earlier also impacted learners. Jumani (2009) wrote that literacy levels in Pakistan were "enhanced through distance and non- formal education with the help of radio" (p. 185). He continued to explain that radio was powerful in the Pakistan literacy campaign "by motivating... and encouraging the individual learning (through) literacy instruction" (p. 184). Nearly a half of a century earlier educators in Belize's neighboring country, Nicaragua, had also utilized school radio. A study conducted in 1979 by Jamison, Searle, Galda, and Heynemen (1981) described the "availability of the radio instructional program" on math instruction which "increased student posttest scores 14.9 items, about 1.5 standard deviations" (p. 556). Leveraging the use of the radio for school, which other countries had found powerful, became an opportunity for Belizean educators.

\section{A Lesson from their Own Past: School Radio}

The use of radio to reach its own country's learners was not new to educators in Belize either. In Belize's infancy, the radio was used to broadcast school lessons, as Babb (2020) recalls,

Long ago and far away, we had a radio broadcast. We knew that it worked then. That was one way of reaching remote students. That was one way of trying to level the playing field. Back in those days, there was no tv, but there was radio. It was called the 'school broadcast.' (Babb, personal communication, [phone interview], May 18, 2020)

Broadcasting school on the national radio station had played a critical role in building Belize as a nation and as a culture after its independence in 1981. The Chief Executive Officer of FM Love, Belize's largest radio station, Neulin Villanueva (2020) remembered the very early years. "School broadcasting started for me way back when I was 15 or 16 years old. I was a young boy listening to Radio Belize." Villanueva continued to recall the national radio's role in school during the birth of Belize as a country.

At the time, it was the only radio broadcasting system in the country of Belize. It was a powerful radio station. There was no other electronic media in the country. At that time, we were just talking about independence about building a nation!! School broadcasts played a key part, a key role of nation building!! (Rene Villaneuva, personal communication, [focus group], May 19, 2020)

Villanueva explained at that time in the Belize's history, the fledgling government "bought a whole set of battery radios for the schools. It had to be battery, because electricity in those days was very unreliable. Then there was school broadcast for the schools that had the radios" (Rene Villaneuva, personal communication, [focus group], May 19, 2020). Now, in this global crisis, searching for a meaningful way to reach their young citizens, once again, Belizeans found themselves catapulted into action. Bruner (1993) described the "quest for meaning within their culture" as "cause for human action" (p. 20). Villaneuva continued to reflect on the rebirth of Belize's school radio.
That was how school broadcasting started. It was discontinued as the roads to access schools improved, but now COVID 19 has caused the Ministry of Education to reinvent the wheel, to come right back in full circle and bring back these school broadcasts. I am sure Dr. Babb, herself, listened to these broadcasts when she was very young. (Rene Villaneuva, personal communication, [focus group], May 19, 2020)

Babb, in fact, had brought radio into her own classroom as a young teacher. She chuckled as recalled, "I remember even in as a classroom teacher, we used to take our radio to school for students to listen the school broadcast" (Carol Babb, personal communication, [phone interview], May 18, 2020). Drawing on previous experience of school broadcasting from decades earlier, Babb, Villaneuva, and the Ministry of Education began to imagine a COVID version of school radio. Babb explained that multiple Belizean radio stations "broadcast nationwide, so students have multiple opportunities" to access school on the radio. She continued to clarify that "if students miss the lessons, they can hear it again on a local radio or tv station. In the case of WAVE radio station, it is also simulcast on their television" (Carol Babb, personal communication, [phone interview], May 18, 2020). The educators of Belize, along with their comrades in radio, found a multitude of strategies to launch school broadcasts in order to reach the diverse young learners of Belize.

\section{Learning a New Platform}

Babb and Villaneuva had experienced school radio from earlier in their lives. However, young teachers in Belize, volunteering to record lessons for school radio, shared their global teacher peers' apprehension towards the challenge of imagining, learning, and practicing whole new ways of teaching. The thought of reaching students, not in the classroom, but through radio waves traveling to the remote homes of their students, was both daunting and energizing. Heusner recalled:

It was super exciting, but also I was like, 'Woman what did you agree to? You don't have time for this!' But the country was in the middle of the whole lockdown quarantine phase, and I felt like it was absolutely my, and any teacher's, civic duty to accept this call. "YES" was my only response. (Kimberly Heusner, personal communication, [email], May 21, 2020)

Ofni Tzul, a Standard 6 (11 and 12 year-olds) teacher also explained his decision to record lessons for the radio, "I wanted to try it, so I can grow as a teacher, so I can learn more about this technology learning or distance learning because we are uncertain how long this will take, because we are in this technology era." Tzul spoke about his hope to impact his own community, his own culture, as he continued, "I became a teacher, because I want to make a change to my community" (Ofni Tzul, personal communication, [phone interview], May 16, 2020). Perhaps in this global pandemic, Heusner and Tzul mirrored Hebuner's (1923/2008) sense of hope, that in a crisis "new creation is possible. Old forms can be transcended" (p. 350). New ways of teaching and new ways of reaching students began to be imagined and 
then practiced. Babb (2020) reflected that Tzul and Heusner, as teachers, were not alone in their desire to transform their practice in order reach their students. She explained, "For teachers, this is a passion. This is a way to stay connected. This is one way of ensuring their children are learning" (Carol Babb, personal communication, [phone interview], May 18, 2020). With that passion, and with a sense of urgency, the work began.

By the end of April, the school radio that Belize had leveraged to build its nation and its culture, was back with as the 2020 COVID-19 version. Heusner commented, "we immediately started planning and getting our act together" (Kimberly Heusner, personal communication, [email,] May 21, 2020). Tzul explained that each teacher who participated in Belize's radio school broadcasts needed to have "internet, and a computer microphone." He continued,

The ministry trained us in one day how to do the lessons on the radio. - A virtual training. They sent us a template, which included an introduction, time for students to get their materials - and this or that. Then we were able to record our first lesson! (Ofni Tzul, personal communication, [phone interview], May 16, 2020).

The training that the Belize Ministry of Education was able to provide the teachers was critical. By contrast, Ribba (2019) looked at school radio in Kenya. He noted that the many students "were not accessing radio school broadcasts" (p. 1). He continued to explain that the teachers in Kenya lacked the "technical know-how" and that there was a tremendous need "for teachers to be trained on the use" of school radio in order for it to be effective (p. 20). Teachers with the skills and understanding necessary to launch lessons for school radio was an integral part of its success.

Heusner depicted the scramble to prepare for the radio lessons, "when we started, we had to go to our classrooms digging for books and resources. What we didn't have, we drew or made up" (Kimberly Heusner, personal communication, email, May 21, 2020). Tzul commented on his peers' courage, explaining that the teachers were "using what they have, and they do great work. Most of them are not used to it, but they have ventured into it" (Ofni Tzul, personal communication, [phone interview], May 16, 2020).

As with all teachers across our newly COVID-19 impacted planet, the learning curve of shifting instruction to a completely new platform was steep. There were certainly obstacles in reaching learners through school radio. Chander and Sharma (2003) discussed the lack of interaction that school radio afforded in India. They wrote that "radio for educational purposes inherently lacks interaction; instructor feedback, and clarification" (p. 2). Heusner also considered the singular reliance of auditory strategies with her new instructional tool. "I quickly realized how much we were relying on visual lessons and needed to switch that up - to talk a whole lot more. Not just talking - but describing every single step so that our radio listeners could 'see"" (Kimberly Heusner, personal communication, [email]. May 21, 2020). Tzul also explained the initial awkwardness of recording his lessons for the radio, "Yes, sometimes I get nervous, but when I am recording, I imagine myself in my classroom, and that helps" (Ofni Tzul, personal communication, [phone interview], May 16, 2020).

There was also the pressure of delivering instruction to thousands of children across the country with a one-shot opportunity. Heusner described her the struggle:

I am constantly on Google and calling friends making sure we don't look or sound incompetent to our listeners. I have to make sure that what we are teaching to thousands of children is ACCURATE. In your classroom, if you make a human error, it is easier to go in and fix it the next day, but once you've broadcasted, there's no guarantee that yesterday's listeners are back again today. The lesson is gone, and you can't hit 'undo,' so it has to be just right. (Kimberly Heusner, personal communication, [email], May 21, 2020)

The work involved in creating an engaging and "accurate" radio broadcast has ended up requiring more planning than typical classroom teaching. Tzul described how this new way of instruction has occupied his time and his thinking "Sunday I start planning - hours just planning -before going to sleep - always - I am thinking, jotting notes, and surfing YouTube to find something" (Ofni Tzul, personal communication, [phone interview], May 16, 2020). Teachers in Belize immersed themselves in meeting the planning and implementation required to reach their students through school radio.

\section{Reaching Remote Learners}

In this uncharted work of planning and pulling together lessons for the radio, Tzul and Heusner could take solace in the fact that children in Belize were being reached. Dena Chulin (2020) described her seven-year-old daughter, Jasmin's, experience. "Every day, without me reminding her, she goes on the radio herself when they start. She doesn't miss an episode. Sometimes I wonder if she is only one listening to it every day." (Dena Chulin, personal communication, [Facebook message], May 27, 2020) Actually, other Belizean learners listen every day as well. Zilpa Tzib (2020) described her daughter Rachel's experience, "I see Rachel's engagement every day on the radio. She listens and participates in the activities. She enjoys the introduction song and even sings it." Tzib continued to give specific examples of what Rachel, who is also seven years old, is getting from the radio broadcasts:

The stories are mostly Belizean stories or stories that link with the topics. For example, if they are teaching similes, the story will have similes. They will orally ask kids to find the similes in the story and give time for them to answer. Rachel answers the questions. Even though the teachers can't hear Rachel's response, they still praise her! It's excellent! (Zilpa Tzib, personal communication, [Facebook message], May 27, 2020).

Like Tzib's satisfaction with how school radio enhanced Rachel's learning during the COVID-19 closures in Belize, other countries in different times had found similar sentiments. Jumani (2009) found that over $70 \%$ of families in Pakistan years earlier also expressed that "literacy can be enhanced through distance and non-formal education with the help of radio" (p. 185). Lessons of literacy now filled radio 
waves that stretched across the country of Belize, impacting lives of students, families, and teachers.

\section{New Connections and Identities}

While the teachers scrambled to get school radio broadcasts out to Belizean children like Rachel and Jasmin, new partnerships and connections were born. It was precisely through these connections that educators were able to move forward. Azoulay (2020) wrote that in this global education crisis "Partnership is the only way forward" (para 3). Tzul explained the emerging connections with his newfound warriors of literacy amidst learning and teaching in a COVID world, "What I like the most are the teachers I am working with. We don't even know each other. We are just teachers from around the country. We learn from each other" (Ofni Tzul, personal communication, [phone interview], May 16, 2020). Heusner echoed Tzul's sentiments, "There is just this genuine concern for each other and how we are coping with our scripts and adding our own personal touch. The teamwork is really amazing, because I did not have much faith in humanity, but it's there you know" (Kimberly Heusner, personal communication, email, May 21, 2020). Tzul and other Belizean teachers found power in their shared dialogue about innovative ideas of transforming instructional practice to meet this new global crisis.

In conversation, they were changing not only their instructional practice, but their identities as educators. Jumani (2009) also noted that through school radio in Pakistan a "climate for change" was birthed (p. 184). Specifically, he wrote that school radio had the "power to affect and change attitudes" (p. 184). Transformation was interwoven with newly imagined possibilities and practice. As newly imagined worlds became a catalyst for changed practice, shifts in practice afforded new versions of previous selves. Holland et al. (1998) described this phenomena: "People's identities and agency are formed dialectically and dialogically in these 'as if' worlds" (p. 49). In sharing this experience and discussions about what was being imagined, planned, and accomplished, these educators' practice and identity were shaped and molded in new ways that will forever be part of who they are.

As Heusner's identity and her perception of her life experience changed, her newfound faith in humanity may have been extended beyond the teachers of Belize. While teachers put in hours to plan for, and to record, lessons for their country, the radio stations joined their gallant fight for the continued learning of their nation's youngest citizens. The work of radio broadcasting was also changed. Now daytime radio commercials (along with the income that came with them) were traded for reading lessons, math lessons, and whatever other lessons that school needed to broadcast. Villaneuva acknowledged the financial sacrifice for school broadcasts, but explained:

Yes, we would be playing music and doing commercials at that time. It would be commercial time. But, we wanted to cooperate with the Ministry of Education because education, for us, is extremely important. It is an honor to carry these broadcasts. Again, it is like history repeating itself. (Rene Villaneuva, personal communication, [focus group], May 19, 2020)

Villaneuva concluded, "Education is the about the quality of life for our people" (Rene Villaneuva, personal communication, [focus group], May 19, 2020). In addition to teachers, other stake holders in Belize, including the radio broadcasters, were committed to education.

\section{LOOKING FORWARD}

While the country of Belize still relies on the school radio broadcasts, educators also look to the next steps in educating their young citizens. Winthrop (2020b) drew on her experience working with education globally facing emergencies as she wrote that returning to the "routine of schooling always takes much longer than you think" (para 11). Winthrop (2020b) continued to discuss school closures in West Africa and noted that "in the case of Ebola, schools were closed between five and eight months" (para 12 -13). Like the rest of world, Belize's educators are realistic about the near- and long-term future of their classrooms. Babb reflected on the upcoming school year, "There is no definitive start time for the opening of school." She continued, "School will have a new look." In addition to what new "hygienic things are in place," Babb also reflected:

We cannot have 30 students in a classroom anymore. There will be a new norm. All those children can't go to school together on the same day. It's not like we have more buildings or teachers to spread them out." (Carol Babb, personal communication, [phone interview], May 18, 2020).

Longer term solutions are also being considered. As Winthrop (2020b) instructed global educators that immediate responses should be designed as "rapid response activities with longer-term development goals" (para 14) Belizean educators acted. Specifically, Winthrop (2020b) wrote that these "immediate response activities can lay the foundation for reaching long-term goals" (para 14). Certainly, internet and devices are an end goal for Belizean educators as well. Already, in addition to the radio broadcasts, Babb noted, 'for students who have devices and connectivity, we also have the lessons available on our website. MOE@gov.BZ." Babb continued to consider her country's future classrooms.

"I am thinking children will not be able to go to school every single day. What do we do with them? We have to find a way to engage them when they stay at home. The only way to do that is with devices, and I don't know how we will do that. How will we do that?" (Carol Babb, personal communication, [phone interview], May 18, 2020)

Uncertainty weighs on Belize's educators, along with all global educators. Yet, there is also a tremendous sense of resolve and even hope. Babb notes,

"I truly believe that out evil comes good, and out of this crisis there are so many opportunities. One of the major opportunities that I see is that we are forced to get our children technologically ready. We have to ensure every child has a device. I do not know how we will do that. But I believe we will" (Carol Babb, [focus group] May 19, 2020). 
Perhaps Babb's optimism is rooted in her call as an educator. After all, Heubner (1923/2008) claimed: "Education is the openness to a future which is beyond all futures. Education is the protest against present forms that they may be reformed and transformed" (p. 360). In sharing Babb's vision and questions for the future education in Belize, Villaneuva also became philosophical: "God did not create failure. Everything must begin with a hope.” (Rene Villaneuva, personal communication, [focus group], May 19, 2020). Perhaps Villaneuva speaks with experience. As he witnessed not only his own, but his comrades' work, in building Belize, he carries the memory of powerful action through the use of radio. These memories may have forever impacted his identity and sense of agency. Heusner (2020) also reflected on the shift in her identity through her changed experience and practice: "2020 may have brought calamity and economic destruction to the world, but it has brought me peace and a stronger sense of self" (Heusner, [Facebook post], 2020). Moje and Luke (2009) explained that life experience and actions, such as Villenueva and Heusner's "continue to work on our concept of who we are, with the self always changing but also retaining histories of participation that shape how the self acts" (p. 418). The COVID-19 school closures indexed the continuous process of Belizean educators in shaping and reshaping their practice and their identities.

\section{CONCLUSION}

What is remarkable about the school radio broadcasts in Belize, is the collective and innovative nature of this work. How effective school radio is in terms of achievement on standardized test scores in this short time is not the intent of this research. Instead, it is an examination of how teachers, administers, radio broadcasters and families came together across this small and resource poor country with a common vision - to reach young learners wherever they were. Wenger (2002) wrote groups of people with a common vision and practice are a "force to be reckoned with" (p. 85). He continued to write that groups of people engaged in shared practice, shared knowledge, and shared visions, "hold the key to real transformation - the kind that has real effect on people's lives" (p. 85). Certainly, the lives of Jasmin's, Rachel's, and other Belizean students have indeed been impacted in the midst of this global disruption. So too, have the identities and practice of the Tzul, Heusner, and other teachers in Belize. As these educators found a newly formed sense of agency in their ability to adapt and innovate in order to reach learners, they reconstructed their concept of themselves as agents of change.

This small community of Belize acted collectively to respond immediately to the pandemic and its implications for their marginalized students. With limited resources they worked to reach every one of their nation's young learners. Lives, identities, practice and learning were all impacted with these acts of courage and determination. These are the lessons from this small, but powerful, group of Belizeans for educators across the globe, who, in this time of a global pandemic, are searching for a sense of hope and resilience.

\section{REFERENCES}

Azoulay, A. (2020). COVID 12 education response. https:// rb.gy/kuckhk

Azzi-Huck, K \& Shmis, T., (2020). Managing the impact of COVID-19 on education systems around the world: How countries are preparing, coping, and planning for recovery, World Bank blogs. https://rb.gy/wlzdhj

Bazeley, P. (2013). Qualitative data analysis: Practical strategies. Los Angeles, CA: Sage.

Bruner, J. (1993). Acts of meaning. Cambridge, MA: Harvard University Press.

Chandar, U. \& Sharma, R. (2003). Bridges to effective learning through radio. International review of research in open and distant learning, 4(1), 1-14.

Principi, N., \& Esposito, S. (2020). Chloroquine or hydroxychloroquine for prophylaxis of COVID-19. The Lancet Infectious Diseases.

Goodson, I. (1992). Studying teachers' lives. London: Routledge.

International Monetary Fund. (2015). World economic outlook: Uneven growth: Short- and long-term factors. Washington, DC.

International Monetary Fund. (2019). World economic outlook: Uneven growth: Short- and long-term factors. Washington, DC. https://rb.gy/27fxlm

Holland, D., Lachicotte, W., Cain, C. \& Skinner, D. (1998). Identity and agency in cultural worlds. Cambridge, MA: Harvard University Press.

Jamison, D. T., Searle, B., Galda, K., \& Heyneman, S. P. (1981). Improving elementary mathematics education in Nicaragua: An experimental study of the impact of textbooks and radio on achievement. Journal of Educational psychology, 73(4), 556.

Jumani, N.B. (2009). Study on role of radio for rural education in Pakistan. Turkish Online Journal of Online Education, 10(4), 176-187. https://rb.gy/slusab

Kim, L. \& Asbury, K. (2020). Like a rug has been pulled under you: The impact of COVID-19 on teachers in England during the first six weeks of the UK lockdown. Psyarxiv Preprints.1-25. https://psyarxiv.com/xn9ey/

Lancker, W.V. \& Parolin, Z. (2020). Covid-19, school closures, and child poverty: a social crisis in the making. Lancet. https://rb.gy/rogmv6

Loh, J. (2013). Inquiry into Issues of Trustworthiness and Quality in Narrative Studies: A Perspective. The Qualitative Report, 18(33), 1-15.

Mohamed, A. (2020). UNESCO rallies international organizations, civil society and private sector partners in a broad coalition to ensure \#LearningNeverStops, UNESCO. https://rb.gy/pb4t3q

Moje, E. B., \& Luke, A. (2009). Literacy and identity: Examining the metaphors in history and contemporary research. Reading Research Quarterly, 44(4), 415-437.

Moss, G. (2004). Provisions of trustworthiness in critical narrative research: Bridging intersubjectivity and fidelity. The Qualitative Report, 9(2), 359-374.

Nash, V. \& Enyon, R. (2020). Coronavirus school closures impact 1.3 billion children - and remote learning is in- 
creasing inequality. The Conversation. https://rb.gy/ yv9q0p

Ribba, E. (2019). Factors affecting radio broadcasts to schools in Kenya: A case study of public primary schools in Rangwe Division, Homa, Bay County. International journal of recent innovations in academic research, 3(11), 1-23.

Rich, M., Dooley, B., \& Inoue, M. (2020). Japan shocks parents by moving to close all schools over coronavirus. The New York Times, https://rb.gy/mgfb6a

Schwandt, T. A. (2015). The sage dictionary of qualitative inquiry ( $4^{\text {th }}$ ed.). Thousand Oaks, CA: Sage Publications.

Thomas, C. J., (2020). Coronavirus and challenging times for developing countries. Brookings. https://rb.gy/qbu1zd

UNESCO. (2020). COVID 12 education response. https:// rb.gy/kuckhk

Vegas, E. (2020). School closures, government responses, and learning inequality around the world during COVID-19. Brookings. https://rb.gy/urdhwn
Viner, R.M., Russel, S, Croker, H, Packer, J, Ward, J, Stansfield, C, Mytton, O, Bonell, C, Booy, R. (2020). School closure and management practices during coronavirus outbreaks including COVID-19: a rapid systemic review. The Lancet. https://rb.gy/zyvbwt

Wenger, E. (2002). Communities of practice learning meaning and identity. Cambridge, UK: Cambridge University Press.

Winthrop, R. (2020a). Top ten risks and opportunities for education in the face of COVID-19 Brookings. https:// rb.gy/tbowjn

Winthrop, R. (2020b). COVID and school closures: What can countries learn from past closures? Brookings. https://rb.gy/ctwu $4 n$

Zhang, W., Wang, Y., Yang, L., and Wang, C. (2020). Suspending classes without stopping learning: China's education emergency management policy in the COVID-19 outbreak. Journal of risk and financial management, 13(55), 1-6. 